\title{
Generation of recombinant single-chain antibodies neutralizing the cytolytic activity of vaginolysin, the main virulence factor of Gardnerella vaginalis
}

\author{
Milda Pleckaityte*, Edita Mistiniene, Rita Lasickiene, Gintautas Zvirblis and Aurelija Zvirbliene
}

\begin{abstract}
Background: Gardnerella vaginalis is identified as the predominant colonist of the vaginal tract in women with bacterial vaginosis. Vaginolysin (VLY) is a protein toxin released by G. vaginalis. VLY possesses cytolytic activity and is considered as a main virulence factor of $G$. vaginalis. Inhibition of VLY-mediated cell lysis by antibodies may have important physiological relevance.

Results: Single-chain variable fragments of immunoglobulins (scFvs) were cloned from two hybridoma cell lines producing neutralizing antibodies against VLY and expressed as active proteins in E. coli. For each hybridoma, two variants of anti-VLY scFv consisting of either $\mathrm{VL}-\mathrm{VH}$ or $\mathrm{VH}-\mathrm{VL}$ linked with a 20 aa-long linker sequence $\left(\mathrm{G}_{4} \mathrm{~S}\right)_{4}$ were constructed. Recovery of scFvs from inclusion bodies with subsequent purification by metal-chelate chromatography resulted in VLY-binding proteins that were predominantly monomeric. The antigen-binding activity of purified scFvs was verified by an indirect ELISA. The neutralizing activity was investigated by in vitro hemolytic assay and cytolytic assay using HeLa cell line. Calculated apparent $K_{d}$ values and neutralizing potency of scFvs were in agreement with those of parental full-length antibodies. VH-VL and VL-VH variants of scFvs showed similar affinity and neutralizing potency. The anti-VLY scFvs derived from hybridoma clone 9B4 exhibited high VLYneutralizing activity both on human erythrocytes and cervical epithelial HeLa cells.

Conclusions: Hybridoma-derived scFvs with VLY-binding activity were expressed in E. coli. Recombinant anti-VLY scFvs inhibited VLY-mediated cell lysis. The monovalent scFvs showed reduced affinity and neutralizing potency as compared to the respective full-length antibodies. The loss of avidity could be restored by generating scFv constructs with multivalent binding properties. Generated scFvs is the first example of recombinant single-chain antibodies with VLY-neutralizing activity produced in prokaryote expression system. G. vaginalis caused infections continue to be a world-wide problem, therefore neutralizing recombinant antibodies may provide novel therapeutic agents useful in the treatment of bacterial vaginosis and other diseases caused by G. vaginalis.
\end{abstract}

\section{Background}

Gardnerella vaginalis is a facultative anaerobic bacterium of the Bifidobacteriaceae family and the sole member of the genus Gardnerella [1]. G. vaginalis is the predominant microorganism of the vaginal tract in women with bacterial vaginosis (BV) [2,3]. BV is highly prevalent, affecting almost one third of women [4].

\footnotetext{
* Correspondence: mildap@ibt.lt
Institute of Biotechnology, Vilnius University, Graiciuno 8, LT-02241, Vilnius,

* Correspondence: mildap@ibt.lt
Institute of Biotechnology, Vilnius University, Graiciuno 8, LT-02241, Vilnius, Lithuania
}

ciated with several serious adverse outcomes including preterm birth and infertility [2,5], endometritis [6], and acquisition of other sexually transmitted infections [7]. Moreover, G. vaginalis has been linked with infections outside the reproductive system. It has been demonstrated that G. vaginalis may cause urinary tract infections in men [8], retinal vasculitis [9], acute hip arthritis in a renal transplant recipients [10], vertebral osteomyelitis [11] and bacteremia in a previously healthy man [12]. These data indicate that G. vaginalis may be more 
virulent than previously expected. It was demonstrated that certain strains of $G$. vaginalis are able to form biofilms $[3,13]$. The genomic analysis support findings on G. vaginalis virulence features such as its ability to adhere to vaginal epithelium, biofilm formation, cytotoxic activity and also provides other features important to the role of G. vaginalis in BV development $[14,15]$.

The main virulence factor of G. vaginalis is the protein toxin vaginolysin (VLY) $[16,17]$. The VLY belongs to the cholesterol-dependent cytolysins (CDCs), a family of pore-forming toxins [18]. These toxins disrupt plasma membranes causing cell lysis and are thought to play a key role in the virulence of bacteria [18]. VLY is a toxin specific to human cells as it recognizes the complement regulatory molecule CD59 $[17,19,20]$. Taken together the virulence properties of G. vaginalis allow the bacteria to adhere to the vaginal epithelium, produce a biofilm and secrete VLY that leads to cytolysis and tissue destruction [3].

The high recurrence rate of BV after antibiotic treatment or persistent BV over time [21,22] may prompt the development and use of recombinant antibodies as novel therapeutic agents for disease treatment. The effectiveness of neutralizing recombinant antibodies against other bacterial toxins, such as pneumolysin, Shiga toxin, Clostridium difficile toxin A, Salmonella $S p v B$ toxin, heat-labile toxin from enterotoxigenic $E$. coli, botulinum neurotoxin has been demonstrated in previous studies [23-29]. Recombinant antibodies neutralizing the cytolytic activity of VLY have not yet been described.

Recently, we have developed a panel of monoclonal antibodies (MAbs) against VLY and demonstrated the ability of some MAbs to prevent the lysis of human erythrocytes in vitro [30].

In the current study, the hybridomas producing wellcharacterized MAbs 9B4 and 23A2 with the most potent VLY neutralizing activity were selected to construct recombinant single-chain variable fragments of immunoglobulins (scFvs). The scFvs were produced in E. coli, purified and characterized in comparison with the fulllength parental MAbs. The ability of $\mathrm{scFv}$ to inhibit cytolytic activity of VLY in vitro has been demonstrated. Construction of recombinant scFv with a potent VLYneutralizing activity may be considered as a first step in developing novel immunotherapeutic tools for the treatment of BV and other diseases caused by G. vaginalis.

\section{Methods}

\section{Cloning and expression of anti-VLY scFvs}

Total mRNA was isolated from $3 \times 10^{6}$ hybridoma cells producing neutralizing MAbs 9B4 and 23A2 [30]. Hybridoma cells were lysed in solution containing guanidine thiocyanate and extracted with phenol-chloroform at reduced $\mathrm{pH}$ [31]. The first strand of $\mathrm{cDNA}$ was prepared using RevertAid ${ }^{\mathrm{TM}} \mathrm{H}$ Minus First Strand cDNA Synthesis Kit (Thermo Scientific Fermentas, Vilnius, Lithuania) according to manufacturer's instructions. The cDNA corresponding to the variable region of mouse IgG was obtained using sets of specific primers described previously [32]: 1) Mouse heavy chain constant region primer: 5'-TTAATAGACAGATGGGGGTGTCGTTTTGGC and mouse heavy chain FR1 region high degenerate primer 5'CATATGSARGTNMAGCTGSAGSAGTC; 2) Mouse kappa chain constant region primer: 5'-TTAGGATACAGTTGGTGCAGCATC and mouse kappa chain FR1 region universal degenerated primer: 5'-CATATGGAYATTGTGMTSACMCARWCTMCA. For each chain, 5 separate clones were selected. Cloned DNA fragments were sequenced and found to be identical in all 5 clones. In a second PCR round, additional primers designed to introduce the 20 amino acid (aa)-long linker sequence $\left(\mathrm{G}_{4} \mathrm{~S}\right)_{4}$ and NdeI/XhoI restriction sites were used. The VL and VH DNA fragments were fused in different orientation to result constructions $\mathrm{VL}-\left(\mathrm{G}_{4} \mathrm{~S}\right)_{4}-\mathrm{VH}$ and $\mathrm{VH}-\left(\mathrm{G}_{4} \mathrm{~S}\right)$ 4 -VL, respectively. The polymerase chain reactions (PCR) were carried out under standard conditions using High Fidelity PCR Enzyme Mix (Thermo Scientific Fermentas). The resulted DNA fragments encoding anti-VLY scFv were introduced by ligation into expression vector pET28a (+) (Merck, Darmstadt, Germany) digested with restriction endonucleases NdeI and XhoI (Thermo Scientific Fermentas). The expression plasmids were transfected into $E$. coli BL21(DE3) strain. The anti-VLY scFv synthesis was induced with $0.5 \mathrm{mM}$ IPTG (isopropyl- $\beta$-D-thiogalactopyranoside) (Thermo Scientific Fermentas). After induction, the cell pellet was disrupted by sonication and centrifuged. The supernatant (soluble fraction) and the cell pellet (insoluble fraction) were then analyzed by $12.5 \%$ polyacrylamide gel electrophoresis (SDS-PAGE) under reducing conditions.

\section{Purification of anti-VLY scFvs}

E.coli biomass containing anti-VLY scFv was homogenised in $100 \mathrm{ml}$ (ratio 1:10, biomass:buffer) of $0.1 \mathrm{M}$ Tris- $\mathrm{HCl}$ buffer ( $\mathrm{pH} 7.0$ ) with $5 \mathrm{mM}$ EDTA, $0.1 \%$ lysozyme, $0.1 \%$ Triton X-100, $1 \mathrm{mM}$ phenylmethylsulphonylfluoride (PMSF) and 2-mercaptoethanol. The homogenizate was stirred for $30 \mathrm{~min}$ at room temperature (RT), sonicated and centrifuged for $25 \mathrm{~min}$ at $24,500 \mathrm{~g}$. The pellet was washed twice with $100 \mathrm{ml}$ of 1 $\mathrm{M} \mathrm{NaCl}$ containing $0.1 \%$ Tween 80 and then with 100 $\mathrm{ml}$ of distilled water. After each washing cycle, the suspension was centrifuged for $25 \mathrm{~min}$ at $24,500 \mathrm{~g}$. The pellet containing inclusion bodies after the last washing cycle was solubilised in $10 \mathrm{mM}$ Tris- $\mathrm{HCl}(\mathrm{pH}$ 7.0) containing $7 \mathrm{M}$ guanidine hydrochloride $(\mathrm{GuHCl})$. The suspension was stirred overnight at $4{ }^{\circ} \mathrm{C}$, centrifuged for 
$25 \mathrm{~min}$ at 40,000 $\mathrm{g}$ and the supernatant was diluted with $10 \mathrm{mM}$ Tris- $\mathrm{HCl}$ buffer ( $\mathrm{pH} 7.0)$ containing $6 \mathrm{M} \mathrm{GuHCl}$ to the final protein concentration of $1 \mathrm{mg} / \mathrm{ml}$. The renaturation of anti-VLY scFvs was performed by adding $\mathrm{CuSO}_{4}$ solution to the final concentration of $20 \mu \mathrm{M}$ and incubation for $1 \mathrm{~h}$ at RT. The reaction was stopped by adding EDTA solution to the final concentration of 10 $\mathrm{mM}$. Protein solution was centrifuged for $25 \mathrm{~min}$ at $40,000 \mathrm{~g}$ and the supernatant was loaded onto the Sephadex G-25 column equilibrated with $25 \mathrm{mM}$ Tris$\mathrm{HCl}$ buffer ( $\mathrm{pH} 8.0$ ) containing $0.25 \mathrm{M} \mathrm{Na}_{2} \mathrm{SO}_{4}$. Fractions with the target protein were collected, pooled and loaded onto the Ni (II) NTA column (Qiagen, Hilden, Germany) (loading buffer: $25 \mathrm{mM}$ Tris- $\mathrm{HCl}, \mathrm{pH}$ 8.0). The elution was performed with the same buffer supplemented with $1 \mathrm{M}$ imidazole. Fractions containing purified anti-VLY scFv were collected, dialyzed against buffer containing $20 \mathrm{mM}$ Tris- $\mathrm{HCl}$ (pH 8.0), $50 \mathrm{mM}$ $\mathrm{NaCl}$ and sterile filtered for long term storage.

Aliquots of purified scFv $(8 \mu \mathrm{g})$ were loaded onto TSK-gel G2000 SWXL column $(7.8 \times 300 \mathrm{~mm})$ (Tosoh Bioscience, Tokyo, Japan). Proteins were eluted with 50 $\mathrm{mM}$ phosphate buffer ( $\mathrm{pH}$ 7.2) supplemented with 0.15 $\mathrm{M} \mathrm{NaCl}$ at a flow rate of $0.5 \mathrm{ml} / \mathrm{min}$, and detected by UV absorbance at 215 and $280 \mathrm{~nm}$.

The antigen-binding activity of scFv were analysed by an indirect ELISA as described below.

\section{Determination of the antigen-binding activity of scFvs by an indirect ELISA}

Microtiter plates (Nunc MaxiSorp, Nunc, Rosikilda, Denmark) were coated with recombinant purified VLY [30] by adding $100 \mu \mathrm{l}$ of VLY solution $(5 \mu \mathrm{g} / \mathrm{ml})$ in coating buffer (50 mM Na-carbonate, $\mathrm{pH} 9.5$ ) and incubation overnight at $4{ }^{\circ} \mathrm{C}$. The plates were blocked for $1 \mathrm{~h}$ at RT with $2 \%$ bovine serum albumin (BSA) in phosphate-buffered saline (PBS) and then incubated with purified $\mathrm{scFv}$ for $1 \mathrm{~h}$ at RT. After washing, the plates were incubated for $1 \mathrm{~h}$ at RT with anti-His5 MAb (Qiagen, Hilden, Germany) diluted 1:1000 in PBS with 0.1\% Tween 20 (PBST) and then incubated for $1 \mathrm{~h}$ with goat anti-mouse IgG labelled with horse-radish peroxidase (HRP) (BioRad, Richmond, CA, USA) diluted 1:2000 in PBST. After washing, the enzymatic reaction was developed with TMB substrate (Sigma-Aldrich, St. Louis, USA) and stopped by adding $1 \mathrm{M} \mathrm{H}_{2} \mathrm{SO}_{4}$. The optical density was measured at $450 \mathrm{~nm}\left(\mathrm{OD}_{450}\right)$ in a microtiter plate reader (Tecan, Groedig, Austria). The apparent dissociation constant $\left(\mathrm{K}_{\mathrm{d}}\right)$ of the scFvs was determined by an indirect ELISA as previously described for fulllength MAbs [30]. Briefly, scFvs were incubated in VLYcoated plates at concentrations ranging from $50 \mu \mathrm{g} / \mathrm{ml}$ to $20 \mathrm{ng} / \mathrm{ml}$. The plates were incubated with anti-His5 MAb (Qiagen) and HRP-labelled anti-mouse IgG
(BioRad) and then developed with TMB substrate. The apparent $K_{d}$ was calculated from a titration curve and defined as a molar concentration of scFv corresponding to the mid-point between maximum $\mathrm{OD}_{450}$ value and the background.

\section{Hemolytic in vitro assay using human erythrocytes}

The use of human erythrocytes from healthy adult volunteer following written informed consent was approved by the Council of the Institute of Biotechnology (Protocol of 30/03/2010, no. 3). In vitro neutralization of VLY hemolytic activity by anti-VLY scFv was analysed as described previously [30]. Briefly, blood was collected by a venipuncture from healthy adult volunteer and anticoagulated with EDTA. Erythrocytes obtained from human blood were isolated by centrifugation, washed and resuspended in sterile PBS. Recombinant VLY (5 ng/ml) was preincubated for $30 \mathrm{~min}$ at RT with serial dilutions of anti-VLY scFv and added to $1 \mathrm{ml}$ of $1 \%$ erythrocyte suspension in PBS. After $15 \mathrm{~min}$ of incubation at RT the cells were pelleted by centrifugation and the released hemoglobin was measured at $415 \mathrm{~nm}$ in a microplate reader (Tecan). As a positive control for the neutralization assay, VLY pre-incubated with the full-length murine MAb 9B4 was included. As a negative control, the erythrocyte suspension was incubated with VLY alone. The $\mathrm{IC}_{50}$ for the scFvs was defined as the concentration of the respective recombinant antibody $(\mathrm{M})$ required for reducing VLY hemolytic activity by $50 \%$.

\section{Cytotoxicity assay using HeLa cell line}

Adherent human cervical epithelial HeLa cells (ATCC Cat. No. CCL-2) were cultivated in RPMI-1640 growth medium (Biochrom, Berlin, Germany) supplemented with $10 \%$ fetal bovine serum (Biochrom) and antibiotics. The cells were grown at $37^{\circ} \mathrm{C}$ and $5 \% \mathrm{CO}_{2}$ in 96-well plates to approx. $70 \%$ confluence. After removing growth medium, the cell monolayer was rinsed twice with serum-free RPMI-1640 medium and then serum-free RPMI-1640 medium was added to the cells $(50 \mu \mathrm{l} /$ well $)$. Recombinant VLY was diluted in serum-free RPMI media and preincubated with serial dilutions of anti-VLY $\mathrm{scFv}$ for $30 \mathrm{~min}$ at RT. The concentration of VLY in each incubation mixture was $6 \mu \mathrm{g} / \mathrm{ml}$, the concentrations of anti-VLY scFv ranged from $1.7 \mathrm{mg} / \mathrm{ml}$ to $4 \mu \mathrm{g} / \mathrm{ml}$. Fiftymicroliters of each mixture were added to the wells with HeLa cells and the plates were incubated for $1 \mathrm{~h}$ at $37^{\circ} \mathrm{C}$ and $5 \% \mathrm{CO}_{2}$. Thus, after adding the incubation mixture ( $50 \mu \mathrm{l} /$ well) to the culture of HeLa cells $(50 \mu \mathrm{l} /$ well $)$ the final concentration of VLY in each well was $3 \mu \mathrm{g} / \mathrm{ml}$. As a negative control, recombinant VLY at the final concentration of $3 \mu \mathrm{g} / \mathrm{ml}$ was used. As a positive control, VLY pre-incubated with the full-length neutralizing monoclonal antibody 9B4 $(50 \mu \mathrm{g} / \mathrm{ml})$ was used. Each sample was 
run in triplicates. After incubation, cell viability was determined by colorimetric assay using 3-(4,5dimethylthiazol-2-yl)-5-(3-carboxymethoxyphenyl)-2-(4sulfophenyl)-2H-tetrazolium (MTS) staining. Twentymicroliters of ready-to-use MTS solution (Promega, Madison, USA) were added to the wells and the plates were incubated for $2 \mathrm{~h}$ at $37^{\circ} \mathrm{C}$ and $5 \% \mathrm{CO}_{2}$. The OD was measured at $490 / 630 \mathrm{~nm}$ wave length in a microplate reader (Tecan). Cell viability was also assessed microscopically at magnifications $40 \times$ and $100 \times$ using microscope Olympus IX-70 (Olympus, Japan).

\section{Analysis of the stability of anti-VLY scFvs in vitro}

In order to evaluate the stability of anti-VLY scFvs, the purified proteins were stored in $20 \mathrm{mM}$ Tris- $\mathrm{HCl}(\mathrm{pH}$ 8.0), $50 \mathrm{mM} \mathrm{NaCl}$ solution at 3 different concentrations: $0.1,0.31$ and $0.65 \mathrm{mg} / \mathrm{ml}$. Protein samples were stored at $4^{\circ} \mathrm{C}$ for 12 months. The stability of the samples stored at $4^{\circ} \mathrm{C}$ was analysed at different time points $(1,3,6,9$, 12 months). Formation of degradation products was evaluated by SDS-PAGE. The neutralizing activity of the stored scFvs was determined by the in vitro hemolytic assay.

\section{Results}

\section{Production of anti-VLY scFvs in E.coli}

The variable regions of the neutralizing anti-VLY MAbs 9B4 and 23A2 were cloned from the respective hybridoma cell lines [30]. The cDNA sequences encoding $\mathrm{VH}$ and VL regions of MAbs 9B4 and 23A2 are deposited in GenBank under accession numbers JF951747, JF951748, JF951745 and JF951746. For each hybridoma clone, two variants of anti-VLY scFvs consisting of either VL-VH or VH-VL linked with 20 aa-long linker sequence $\left(\mathrm{G}_{4} \mathrm{~S}\right)_{4}$ were constructed. The expression plasmids based on pET28a $(+)$ vector bearing anti-VLY scFv encoding genes were transformed into E.coli BL21(DE3) strain. The analysis of soluble and insoluble fractions of transformed $E$. coli cells by SDS-PAGE demonstrated that over $90 \%$ of the recombinant proteins of interest are found in the insoluble fraction (Figure 1A). The expression levels of different anti-VLY scFvs determined by SDS-PAGE were similar and ranged from 20 to $30 \%$ of total cell protein (Figure 1A, Table 1).

The N-terminally hexahistidine-tagged anti-VLY scFvs representing $27.5 \mathrm{kDa}$ proteins were purified from inclusion bodies by renaturation and subsequent application of metal-chelate affinity chromatography. Preparations of purified anti-VLY scFv verified by SDS-PAGE under reducing conditions represented essentially homogenous scFvs (Figure 1B). Size exclusion chromatography of anti-VLY scFvs revealed one major peak with an apparent molecular weight corresponding to monomeric state of scFv (Figure 1C, Table 1). No fractions corresponding to the oligomeric forms of $\mathrm{scFv}$ were eluted from the column. This indicated the low tendency of generated anti-VLY scFvs to form multimeric structures. Thus, after renaturation and purification steps four variants of monovalent scFvs derived from the respective hybridomas $9 \mathrm{~B} 4$ and 23A2 were obtained.

Neutralization of VLY hemolytic activity by anti-VLY scFvs The ability of anti-VLY scFvs to inhibit the hemolytic activity of VLY was investigated using human

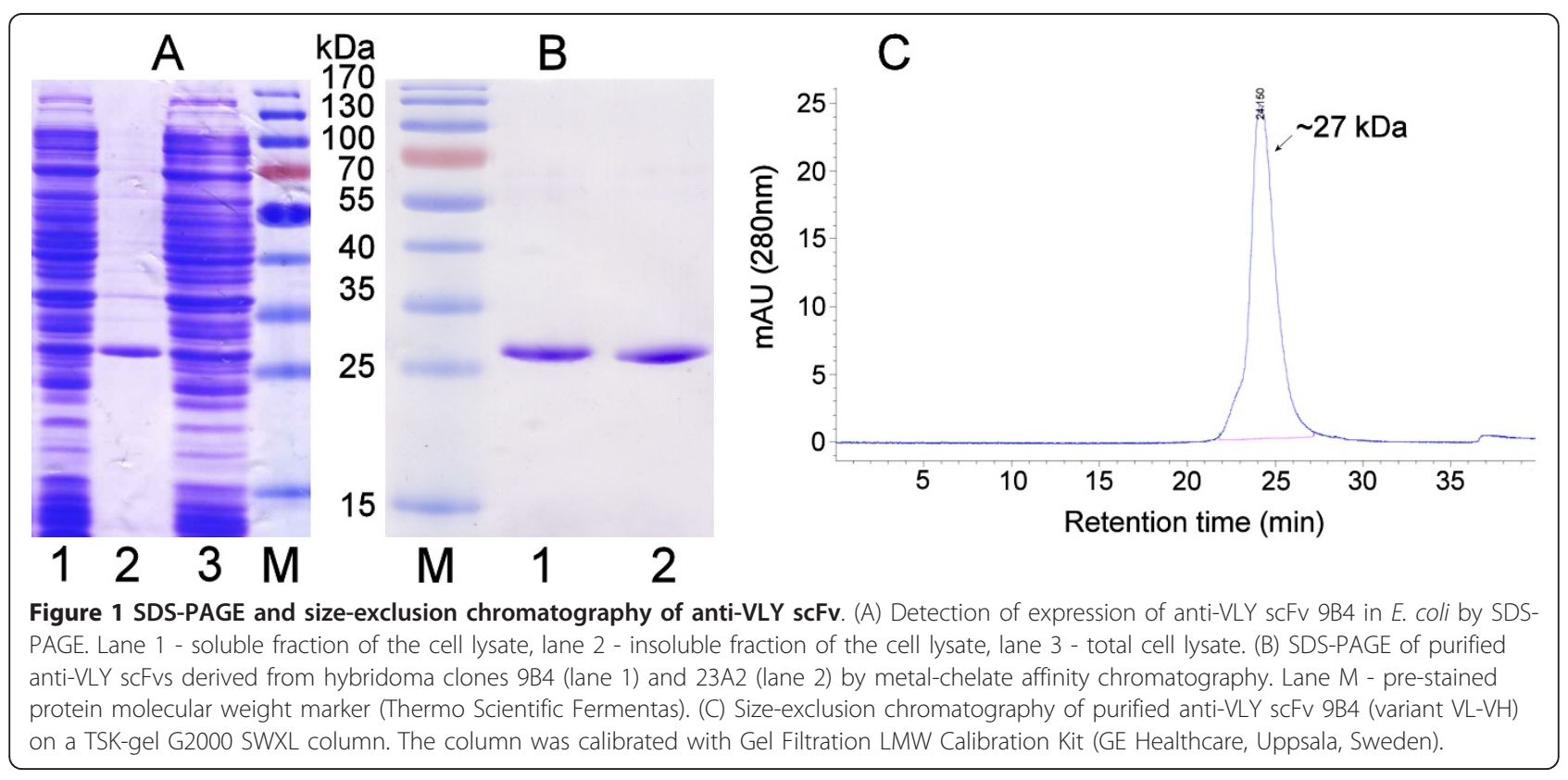


Table 1 Expression level and stability of anti-VLY scFvs

\begin{tabular}{cccc}
\hline Anti-VLY scFv & Expression level, \% of total cell protein & Oligomeric state & Activity (\%) after 12 months storage at $\mathbf{4}^{\circ} \mathrm{C}$ \\
\hline scFv 9B4 (VL-VH) & $20-30$ & monomeric & 100 \\
scFv 9B4 (VH-VL) & $20-30$ & monomeric & 100 \\
scFv 23A2 $(\mathrm{VL}-\mathrm{VH})$ & $20-30$ & monomeric & 75 \\
scFv 23A2 $(\mathrm{VH}-\mathrm{VL})$ & $20-30$ & monomeric & 75 \\
\hline
\end{tabular}

erythrocytes. In our previous study the MAbs $9 \mathrm{~B} 4$ and 23A2 have been shown to neutralize the activity of VLY and prevent the lysis of human erythrocytes in vitro. The MAb 23A2 was shown to exhibit fair neutralizing activity $\left(\mathrm{IC}_{50}=4.8 \times 10^{-10} \mathrm{M}\right)$ while the MAb 9B4 showed the more potent neutralizing activity $\left(\mathrm{IC}_{50}=6.7\right.$ $\times 10^{-11} \mathrm{M}$ ) [30]. We have analysed the neutralizing potency of different anti-VLY scFv constructs in comparison with that of full-length MAbs 9B4 and 23A2. All purified anti-VLY scFvs were able to neutralize the hemolytic activity of VLY (Figure 2, Table 2). The $\mathrm{IC}_{50}$ values calculated from concentration-dependent curves ranged from $3.7 \times 10^{-8}$ to $1.5 \times 10^{-7} \mathrm{M}$. The anti-VLY scFvs, both VL-VH and VH-VL variants, derived from the parental hybridoma clone 9B4 exhibited stronger neutralizing activity $\left(\mathrm{IC}_{50}=3.7 \times 10^{-8} \mathrm{M}\right.$ and $5.1 \times 10^{-8}$ $M$, respectively) than anti-VLY scFvs derived from hybridoma clone 23A2 $\left(\mathrm{IC}_{50}=1.1 \times 10^{-7} \mathrm{M}\right.$ and $1.5 \times$ $10^{-7} \mathrm{M}$, respectively). The extent of the neutralizing potency of different scFvs was in agreement with that of their parental full-length MAbs (Table 2). The antigenbinding activities of purified scFvs were investigated by an indirect ELISA. All scFv variants recognized recombinant VLY immobilized on the plate and showed moderate binding affinities with the apparent $\mathrm{K}_{\mathrm{d}} 1.1 \times 10^{-8}$ to $9.8 \times 10^{-8} \mathrm{M}$ that was also in line with the affinities of parental full-length MAbs (Table 2). No VLY-neutralizing activity was observed when a control $\mathrm{scFv}$ derived from the non-neutralizing hybridoma clone 10G5 was used (data not shown). A mixture of equal amounts of two different anti-VLY scFvs showed substantially higher neutralizing potency on the hemolytic activity of VLY as compared to single scFv (Figure 2). The additive action of two anti-VLY scFvs on the neutralization of VLY activity indicates the bivalent manner of the mixture of anti-VLY scFvs.

\section{Neutralization of VLY cytolytic activity by anti-VLY scFvs}

The neutralizing potency of anti-VLY scFvs was assayed using human cervical epithelial (HeLa) cells. Lysis of vaginal epithelial cells by VLY is considered to be a key step in progression of bacterial vaginosis and predispose to further complications associated with the disease $[3,20]$. Thus, inhibition of cytolytic activity of VLY may

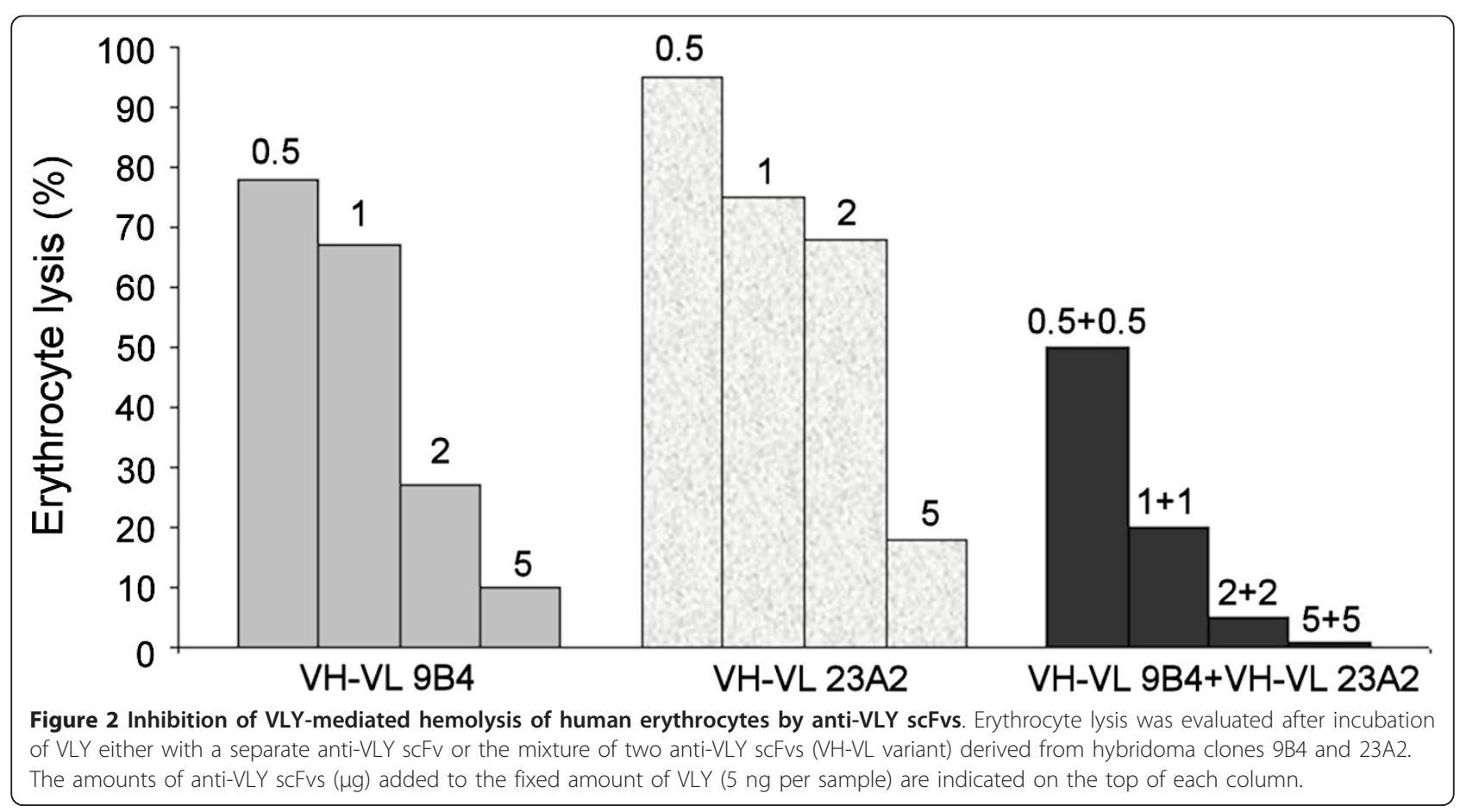


Table 2 Neutralizing activity and affinity of anti-VLY scFvs and the respective MAbs

\begin{tabular}{ccc}
\hline Anti VLY scFv and MAb & $\mathbf{I C}_{\mathbf{5 0}}, \mathbf{M}$ & $\mathbf{K}_{\mathbf{d}}, \mathbf{M}$ \\
\hline scFv 9B4 (VL-VH) & $3.7 \times 10^{-8}$ & $1.1 \times 10^{-8}$ \\
scFv 9B4 (VH-VL) & $5.1 \times 10^{-8}$ & $1.5 \times 10^{-8}$ \\
scFv 23A2 (VL-VH) & $1.1 \times 10^{-7}$ & $9.2 \times 10^{-8}$ \\
scFv 23A2 (VH-VL) & $1.5 \times 10^{-7}$ & $9.8 \times 10^{-8}$ \\
MAb 9B4 & $6.7 \times 10^{-11}$ & $2.9 \times 10^{-10}$ \\
MAb 23A2 & $4.8 \times 10^{-10}$ & $1.2 \times 10^{-10}$ \\
\hline
\end{tabular}

have important physiologic relevance. In a first step the concentration of VLY required for a complete lysis of HeLa cells as well as the dynamics of cytolysis were investigated. For this purpose, the cells were incubated with increasing VLY concentrations (from $1 \mathrm{ng} / \mathrm{ml}$ to $100 \mu \mathrm{g} / \mathrm{ml}$ ) and observed microscopically at different time points $(10-60 \mathrm{~min})$. In parallel, the viability of HeLa cells was measured by colorimetric MTS assay. It was determined that $2.5 \mu \mathrm{g} / \mathrm{ml}$ of VLY is sufficient to induce complete lysis of HeLa cells (Figure 3C). The cytolytic effect of VLY on HeLa cell culture was observed immediately (10 min) after VLY adding. Thus, it was demonstrated that the quantities of VLY required to induce the lysis of HeLa cells are higher than that required to induce the lysis of human erythrocytes ( 2.5 $\mu \mathrm{g} / \mathrm{ml}$ and $5 \mathrm{ng} / \mathrm{ml}$, respectively). The ability of scFvs and the respective full-length MAbs to inhibit VLYmediated cytolysis of HeLa cells was evaluated by colorimetric MTS assay. It was determined that $500 \mu \mathrm{g} / \mathrm{ml}$ of $\mathrm{scFv}$ and $50 \mu \mathrm{g} / \mathrm{ml}$ of full-length antibody $9 \mathrm{~B} 4$ induced complete neutralization of VLY-mediated cytolysis in HeLa culture (Figure 4). In contrast, the scFv derived from hybridoma 23A2 did not inhibit VLY cytolytic activity even at the highest concentration used (1 $\mathrm{mg} / \mathrm{ml}$ ), which is explained by its lower affinity and neutralizing potency (Table 2). In line with these data, the full-length MAb 23A2 was not able to inhibit VLY cytolytic activity at concentration of $50 \mu \mathrm{g} / \mathrm{ml}$ and higher (Figure 4).

\section{Stability of scFvs during long-term storage}

The activity of anti-VLY scFvs stored for 12 months at $4^{\circ} \mathrm{C}$ was tested by determination of their ability to neutralize VLY-mediated lysis of human erythrocytes in vitro. The appearance of possible degradation products was analysed by SDS-PAGE. The protein samples stored at three different concentrations were analyzed at different time points. The SDS-PAGE under denaturing conditions did not reveal any degradation products of antiVLY scFv (VH-VL and VL-VH variants) derived from hybridoma clone $9 \mathrm{~B} 4$ stored for 12 months at $4^{\circ} \mathrm{C}$ even at the highest protein concentration (Figure 5A). However, both variants of $\mathrm{scFv}$ derived from hybridoma clone 23A2 showed minor degradation products when stored for more that 6 months (Figure 5A). The neutralizing potency of VLY hemolytic activity by 23A2derived $\mathrm{scFv}$ declined during storage, while the neutralizing activity of 9B4-derived scFvs remained unchanged (Figure 5B, Table 1). Thus, VH-VL and VL-VH variants of 9B4-derived $\mathrm{scFv}$ were more stable during long-term storage at $4^{\circ} \mathrm{C}$ as compared to 23A2-derived scFvs.

\section{Discussion}

The increasing number of antibiotic resistant bacteria and the severity of infections upgrade the interest in antibody therapy against toxins associated with the development of disease. The high recurrence rate or persistence of infection, inappropriate or controversial treatment with antibiotics, extreme toxicity and potency of the toxins released from killed bacteria are suggested to be the cases applicable for passive immunotherapy $[26,29,33]$. Recombinant scFvs either derived from hybridoma cells or produced by phage display technique remain an attractive alternative to full-length antibodies because of easier and less costly manufacture, opportunity of genetic engineering, tissue penetration and short-circulating half-lives. It was demonstrated by in vitro and in vivo assays that recombinant antibodies neutralize the activity of toxins that are highly diverse in nature and mode of action [23-29]. Hybridomaderived scFvs were shown to neutralize the cytolytic

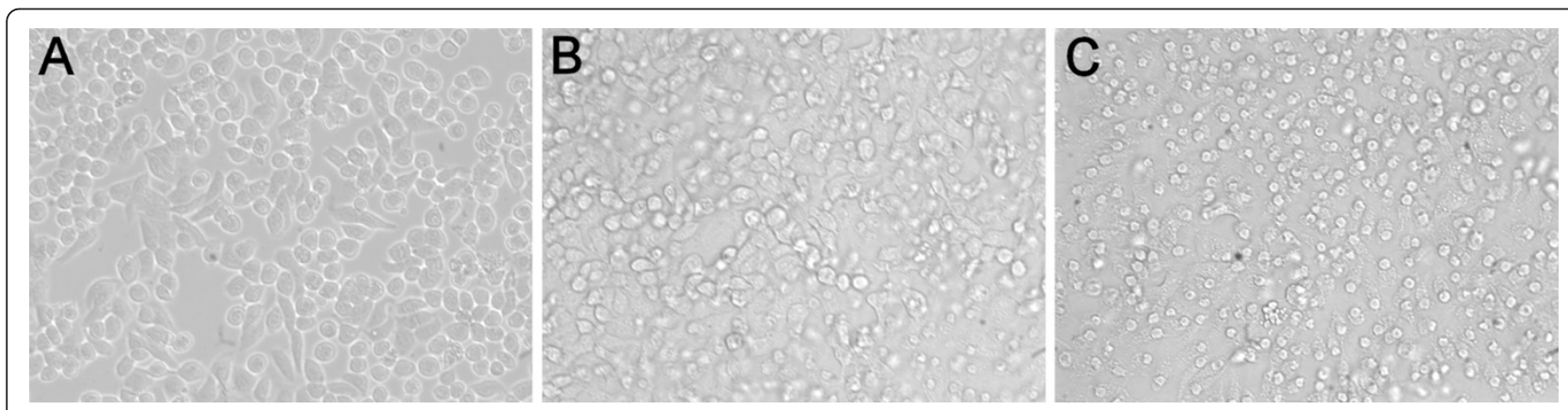

Figure 3 HeLa cell culture after $10 \mathrm{~min}$ of incubation with different concentrations of VLY: $0.03 \mu \mathrm{g} / \mathrm{ml}(\mathrm{A}), 0.3 \mu \mathrm{g} / \mathrm{ml}(\mathrm{B}), 3 \mu \mathrm{g} / \mathrm{ml}$ (C) The cells were observed by microscope Olympus IX-70 at magnification 40X. 


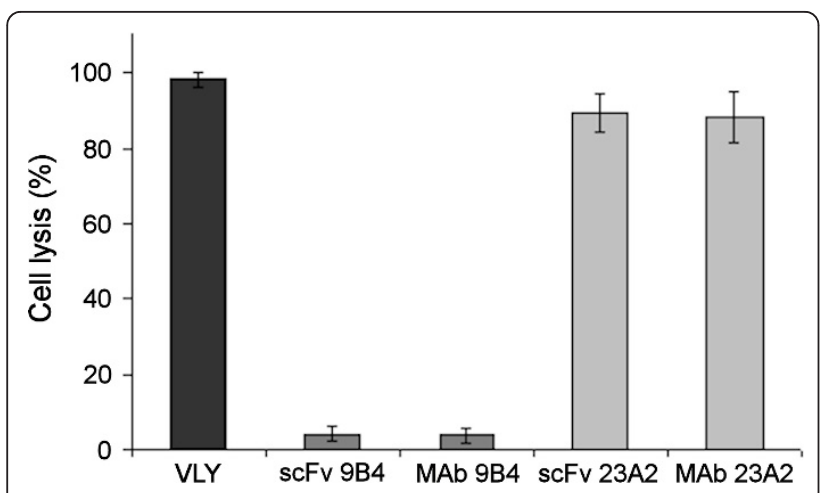

Figure 4 Inhibition of VLY-mediated cytolysis of HeLa cells by anti-VLY scFvs. HeLa cells were exposed to VLY alone $(3 \mu \mathrm{g} / \mathrm{ml})$ or VLY $(3 \mu \mathrm{g} / \mathrm{ml})$ preincubated either with scFvs $(500 \mu \mathrm{g} / \mathrm{ml})$ or fulllength MAbs $(50 \mu \mathrm{g} / \mathrm{ml})$. Cell viability was determined by colorimetric assay using MTS staining. Mean $\mathrm{OD}_{490}$ values $( \pm 2 \mathrm{SD}$ ) were calculated from triplicates. The neutralizing activity of each anti-VLY scFv variant is expressed in \% of cytolysis. Complete cytolysis induced by VLY alone is set $100 \%$.

activity of pneumolysin from Streptococcus pneumonia [23]. Recently, human scFvs derived from a phage display library were developed that neutralize the cytotoxicity of Shiga toxins produced by enterohemorragic $E$. coli bacteria [29]. The efficacy of single domain antibodies ( $\mathrm{VHH}$ ) to neutralize Clostridium difficile toxin A was demonstrated by the in vitro assay [28]. The ability to neutralize botulinum neurotoxin in mice was demonstrated using chimeric antibody generated by fusion of hybridoma-derived scFv with human Fc domain [26].
The secreted toxin VLY is known to be the major virulence factor of G. vaginalis [16,17]. Toxic effect of VLY is based on its ability to form pores in the cell membrane causing cell lysis $[16,17,19]$. Recently, novel murine MAbs 9B4 and 23A2 against VLY were developed and characterized as highly efficient in neutralizing VLY activity in vitro [30]. In the current study, we generated and characterized four functionally active antiVLY scFvs derived from hybridomas $9 \mathrm{~B} 4$ and 23A2. Anti-VLY scFvs with hexahistidine residues at the N-terminus were expressed in E. coli and recovered from the inclusion bodies with subsequent application of metalchelate affinity chromatography.

Purified anti-VLY scFvs inhibited VLY-mediated cytolysis with different efficiency that was in line with the affinity and neutralizing potency of the respective parental MAbs. The anti-VLY scFvs derived from hybridoma 9B4 exhibited high VLY-neutralizing activity both on human erythrocytes and cervical epithelial HeLa cells. Moreover, the 9B4-derived scFvs were shown to be highly stable during long-term storage at $4^{\circ} \mathrm{C}$. Therefore, this construct may be considered as a promising candidate for developing novel therapeutic tools to neutralize cytotoxic effects of VLY.

Interestingly, $\mathrm{VH}-\mathrm{VL}$ and $\mathrm{VL}-\mathrm{VH}$ variants of $\mathrm{scFv}$ showed similar affinity and neutralizing potency. This suggests that the orientation of variable fragments in the construct did not influence dramatically the folding and subsequently the antigen-binding capacity of the scFv. However, recombinant anti-VLY scFvs did not retain all the properties of the respective parental MAbs. The

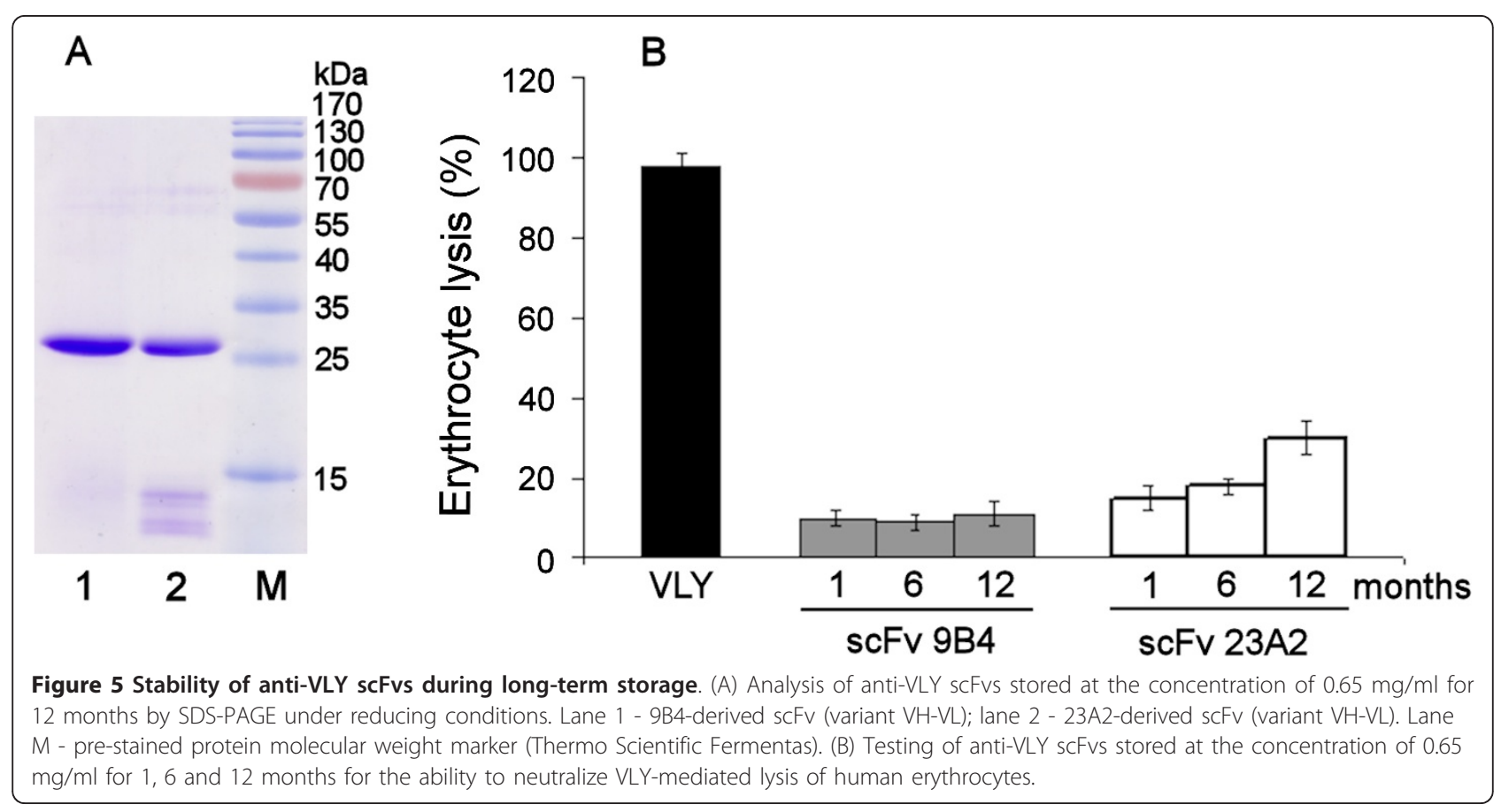


decreased neutralizing potency and reduction in affinity of scFvs as compared to full-length MAbs can be explained by monovalent binding properties, as purified anti-VLY scFvs were found predominantly in a monomeric form. The avidity could be increased by generation of recombinant antibodies with multivalent binding capacity using the scFv multimerization approach or generation of a fusion with the whole Fc fragment of human IgG $[26,34,35]$. The scFvs described in the current study is the first example of recombinant singlechain monovalent antibodies with VLY-neutralizing activity produced in prokaryote expression system.

\section{Conclusions}

We have expressed in E.coli hybridoma-derived scFvs with VLY-binding activity. Anti-VLY scFvs inhibited VLY-mediated lysis of human erythrocytes in vitro and human cervical epithelial HeLa cells. The monovalent scFvs showed reduced affinity and neutralizing potency as compared to the respective parental MAbs. The loss of avidity could be restored by generating $\mathrm{scFv}$ constructs with multivalent binding properties. G. vaginalis caused infections continue to be a world-wide problem, therefore neutralizing recombinant antibodies may provide novel therapeutic tools useful in the treatment of BV and other diseases caused by $G$. vaginalis.

\section{Acknowledgements}

We gratefully acknowledge the financial support by the Research Council of Lithuania (project "Anti-cytolysin", grant number PBP-01/2010) and Postdoctoral Fellowship Implementation in Lithuania program (fellowship number VP1-3.1-ŠMM-01-V-01-001, no. 25)

\section{Authors' contributions}

MP carried out all gene engineering procedures, analysed neutralizing activity of scFvs and drafted the manuscript. EM purified recombinant VLY and SCFvs. RL carried out the immunoassay and cytolytic assay. GZ selected the primers for cloning and helped to interpret experimental data. AZ participated in the design of the study and revised the manuscript. All authors read and approved the final manuscript.

\section{Competing interests}

The authors declare that they have no competing interests.

Received: 8 August 2011 Accepted: 3 November 2011 Published: 3 November 2011

\section{References}

1. Catlin BW: Gardnerella vaginalis: characteristics, clinical considerations, and controversies. Clin Microbiol Rev 1992, 5:213-237.

2. Menard JP, Mazouni C, Salem-Cherif I, Fenollar F, Raoult D, Boubli L, Gamerre M, Bretelle F: High vaginal concentrations of Atopobium vaginae and Gardnerella vaginalis in women undergoing preterm labor. Obstet Gynecol 2010, 115:134-140.

3. Patterson JL, Stull-Lane A, Girerd PH, Jefferson KK: Analysis of adherence, biofilm formation and cytotoxicity suggest a greater virulence potential of Gardnerella vaginalis relative to other bacterial vaginosis-associated anaerobes. Microbiology 2010, 156:392-399.

4. Allsworth JE, Peipert JF: Prevalence of bacterial vaginosis: 2001-2004 National Health and Nutrition Examination Survey data. Obstet Gynecol 2007, 109:114-120.
5. Mania-Pramanik J, Kerkar SC, Salvi VS: Bacterial vaginosis: a cause of infertility? Int J STD \& AIDS 2009, 20:778-781.

6. Haggerty CL, Hillier SL, Bass DC, Ness RB: Bacterial vaginosis and anaerobic bacteria are associated with endometritis. Clin Infect Dis 2004 39:990-995.

7. Schmid G, Markowitz $L$, Joesoef $R$, Koumans $E$ : Bacterial vaginosis and HIV infection. Sex Transm Infect 2000, 76:3-4.

8. Yoon HJ, Chun J, Kim JH, Kang SS, Na DJ: Gardnerella vaginalis septicaemia with pyelonephritis, infective endocarditis and septic emboli in the kidney and brain of an adult male. Int J STD AIDS 2010, 21:653-657.

9. Neri P, Salvolini S, Giovannini A, Meriotti C: Retinal vasculitis associated with asymptomatic Gardnerella vaginalis infection: a new clinical entity. Ocul Immunol Infamm 2009, 17:36-40.

10. Sivadon-Tardy V, Roux AL, Piriou P, Herrmann $J$, Gaillard $J$, Rottman M: Gardnerella vaginalis acute hip arthritis in a renal transplantant recipient. J Clin Microbiol 2009, 47:264-267.

11. Graham S, Howes C, Dusmuir R, Sandoe J: Vertebral osteomyelitis and discitis due to Gardnerella vaginalis. J Med Microbiol 2009, 58:1382-1384.

12. Lagacé-Wiens PR, Ng B, Reimer A, Burdz T, Wiebe D, Bernard K: Gardnerella vaginalis bacteremia in a previously healthy man: case report and characterization of the isolate. J Clin Microbiol 2008, 46:804-806.

13. Swidsinski A, Mendling W, Loening-Baucke V, Ladhoff A, Swidsinski W, Hale LP, Lochs H: Adherent biofilms in bacterial vaginosis. Obstet Gynecol 2005, 106:1013-1023.

14. Yeoman CJ, Yildirim S, Thomas SM, Durkin AS, Torralba M, Sutton G, Buhay CJ, Ding Y, Dugan-Rocha SP, Muzny DM, Qin X, Gibbs RA, Leigh SR, Stumpf R, White BA, Highlander SK, Nelson KE, Wilson BA: Comparative genomics of Gardnerella vaginalis strains reveals substantial differences in metabolic and virulence potential. PLoS One 2010, 5:e12411.

15. Harwich MD Jr, Alves JM, Buck GA, Strauss JF, Patterson JL, Oki AT, Girerd PH, Jefferson KK: Drawing the line between commensal and pathogenic Gardnerella vaginalis through genome analysis and virulence studies. BMC Genomics 2010, 11:375.

16. Cauci S, Monte R, Ropele M, Missero C, Not T, Quadrifoglio F, Menestrina G: Pore-forming and haemolytic properties of the Gardnerella vaginalis cytolysin. Mol Microbiol 1996, 9:1143-1155.

17. Gelber $\mathrm{SE}$, Aguilar $\mathrm{J}$, Lewis $\mathrm{KL}$, Ratner AJ: Functional and phylogenetic characterization of Vaginolysin, the human-specific cytolysin from Gardnerella vaginalis. J Bacteriol 2008, 190:3896-3903.

18. Tweten RK: Cholesterol-dependent cytolysins, a family of versatile poreforming toxins. Infect Immun 2005, 73:6199-6209.

19. Rottini G, Dobrina A, Forgiarini O, Nardon E, Amirante GA, Partiarca P: Identification and partial characterization of a cytolytic toxin produced by Gardnerella vaginalis. Infect Immun 1990, 58:3751-3758.

20. Randis TM, Kulkarni R, Aguilar JL, Ratner AJ: Antibody-based detection and inhibition of vaginolysin, the Gardnerella vaginalis cytolysin. PLOS One 2009, 4:e5207.

21. Bradshaw CS, Tabrizi SN, Fairley CK, Morton AN, Rudland E, Garland SM: The association of Atopobium vaginae and Gardnerella vaginalis with bacterial vaginosis and recurrence after oral metronidazole therapy. J Infect Dis 2006, 194:828-836.

22. Marrazzo JM, Thomas KK, Fiedler TL, Ringwood K, Fredricks DN: Relationship of specific vaginal bacteria and bacterial vaginosis treatment failure in women who have sex with women. Ann Intern Med 2008, 149:20-28.

23. Garcia M, Strachan G, Porter AJ, Harris WJ: Retention of neutralising activity by recombinant anti-pneumolysin antibody fragments. FEMS Immunol Med Microbiol 1998, 22:225-231.

24. Stone E, Hirama T, Chen W, Soltyk AL, Brunton J, Mackenzie CR, Zhang J: A novel pentamer versus pentamer approach to generating neutralizers of verotoxin 1. Mol immunol 2007, 44:2487-2491.

25. Harmsen MM, van Solt CB, Fijten HP: Enhancement of toxin- and virus-neutralizing capacity of single-domain antibody fragments by N-glycosylation. Appl Microbiol Biotechnol 2009, 84:1087-1094.

26. Prigent J, Mazuet C, Boquet D, Lamourette P, Volland H, Popoff MR, Créminon C, Simon S: Production and characterisation of a neutralising chimeric antibody against botulinum neurotoxin A. PLoS One 2010, 5 : e13245.

27. Alzogaray $V$, Danquah $W$, Aguirre A, Urrutia M, Berguer P, García Véscovi $E$ Haag F, Koch-Nolte F, Goldbaum FA: Single-domain llama antibodies as 
specific intracellular inhibitors of SpvB, the actin ADP-ribosylating toxin of Salmonella typhimurium. FESEB J 2011, 25:526-534.

28. Hussack G, Arbabi-Ghahroudi M, van Faassen H, Songer JG, Ng KK,

Mackenzie R, Tanha J: Neutralization of Clostridium difficile toxin A with single-domain antibodies targeting the cell-receptor binding domain. J Biol Chem 2011, 286:8961-8976.

29. Neri P, Shigemori N, Hamada-Tsutsumi S, Tsukamoto K, Arimitsu H, Shimizu T, Akahori Y, Kurosawa Y, Tsuji T: Single chain variable fragment antibodies against Shiga toxins isolated from a human antibody phage display library. Vaccine 2011, 29:5340-5346.

30. Zvirbliene A, Pleckaityte M, Lasickiene R, Kucinskaite-Kodze I, Zvirblis G Production and characterization of monoclonal antibodies against vaginolysin: mapping of a region critical for its cytotoxic activity. Toxicon 2010, 56:19-28.

31. Sambrook J, Russell DW: Molecular cloning, A Laboratory Manual Cold Spring Harbour, Cold Spring Harbor Press; 2001.

32. Wang Z, Raifu M, Howard M, Smith L, Hansen D, Goldsby R, Ratner D: Universal PCR amplification of mouse immunoglobulin gene variable regions: the design of degenerate primers and an assessment of the effect of DNA polymerase $3^{\prime}$ to $5^{\prime}$ exonuclease. J Immunol Methods 2000, 13:167-177.

33. De Marco A: Biotechnology applications of recombinant single-domain antibody fragments. Microb Cell Fact 2011, 10:44.

34. Moutel S, El Marjou A, Vielemeyer O, Nizak C, Benaroch P, Dübel S: A multiFc-species system for recombinant antibody production. BMC Biotechnol 2009, 9:14.

35. Otz T, Grosse-Hovest L, Hofmann M, Rammensee HG, Jung G: A bispecific single-chain antibody that mediates target cell-restricted, supraagonistic CD28 stimulation and killing of lymphoma cells. Leukemia 2009, 23:71-77.

doi:10.1186/1472-6750-11-100

Cite this article as: Pleckaityte et al:: Generation of recombinant singlechain antibodies neutralizing the cytolytic activity of vaginolysin, the main virulence factor of Gardnerella vaginalis. BMC Biotechnology 2011 11:100.

\section{Submit your next manuscript to BioMed Central and take full advantage of:}

- Convenient online submission

- Thorough peer review

- No space constraints or color figure charges

- Immediate publication on acceptance

- Inclusion in PubMed, CAS, Scopus and Google Scholar

- Research which is freely available for redistribution

Submit your manuscript at www.biomedcentral.com/submit 